\begin{tabular}{l}
$\begin{array}{r}\text { Squalen Bull. of Mar. \& Fish. Postharvest \& Biotech. } 10 \text { (1) 2015, 9-15 } \\
\text { www.bbp4b.litbang.kkp.go.id/squalen-bulletin } \\
\text { Squalen Bulletin of Marine \& Fisheries Postharvest \& Biotechnology } \\
\text { ISSN: 2089-5690 } \\
\text { e-ISSN: 2406-9272 }\end{array}$ \\
\hline
\end{tabular}

\title{
SCREENING OF SIGNIFICANT VARIABLES FOR SLICED FRYING FISH BALL USING PLACKETT-BURMAN DESIGN
}

\author{
Syamdidi* and Theresia Dwi Suryaningrum \\ Research and Development Center for Marine and Fisheries Product Processing and Biotechnology, \\ JI. Ks. Tubun Petamburan VI Slipi Jakarta Pusat 10260, Indonesia. \\ Article history: \\ Received: 2 December 2014; Revised: 10 March 2015; Accepted: 4 April 2015
}

\begin{abstract}
Screening of significant variables of Sliced Frying Fish Ball (Basreng) has been conducted using Plackett-Burman Design, a statistical method commonly used to reveal the significance of variables in the product development. Four variables were selected namely tapioca flour, potato flour, fish, and frying time. Twelve formulations were peformed and the final products were analyzed for their sensory and texture parameters. Six responses were chosen (appearance, color, odor, taste, texture, overall acceptance and hardness) and then evaluated based on their significance, coefficient value and ranking test through appropriate statistical analysis. The result showed that four variables gave positive and negative effects to the products. Based on overall ranking test, tapioca flour was placed at the first place meaning that it had highest desirable properties followed by frying time, potato flour, and fish flesh. The overall rank test for each ingredient and the attributes provided a reliable data/information to select the most compatible ingredients for further optimization experiment.
\end{abstract}

Keywords: quick and reliable screening, compatible factors, sliced fried fish ball, Plackett-Burman Design

\section{Introduction}

Fish ball are a common food in Indonesia which is a restructured product made from meat and filler (flour and other ingredients) (Purnomo, 1997). There are varieties of fish ball in the market based on their protein content which called "super" for higher protein and "ordinary" for lower protein content. Nowadays, in line with the growth of snack industries, fish ball is not only served as boiled product but also as fried product in thin sliced form. This sliced fried fish ball (then called basreng) is becoming popular in Indonesia. Hence, some of fish ball industries change their product from boiled into fried product. Some of them have successfully produced good products. Most of the successfully developed basreng were found in West Java, especially in Bandung. Before, Basreng was commonly known as a gift from someone who traveling from West Java, but currently, industries have spread out due to high market demand. As the result, basreng small scale industries are extensively growing not only in West Java but also in other areas such as Jakarta.

\footnotetext{
${ }^{*}$ Corresponding author.

E-mail: didibangka@yahoo.com
}

Technology of fish ball-making is generally well known being applied worldwide using flour as a binder and filler. Tapioca flour is commonly used as filler in making fish ball since it is known as a source of amylopectin. As binder and filler, tapioca has the ability (Usmiati, 2009) to help gelatinization during fish ball processing, by producing viscous and firm product (Astawan \& Astawan, 1989; Sunarlim, 1994). It was reported that tapioca gave a significant effect on protein content and physical properties as well as binder activity of other ingredients (Astawan \& Astawan, 1989). Other type of flour, such as potato flour, is also generally used as filler in extruded product (Iwe et al., 1998) and other similar product including snacks.

Basreng is formulated in the same way as the original fish ball except for the frying process conducted over the boiling step. Ingredients used for basreng are similar with ingredients for fish ball but include some modifications to produce dense and crispy product. Flour, amount of fish flesh and frying time are allegedly influencing the quality of basreng. Basreng is applying vacuum frying method which is usually used for frying high-moisture product such as fruit snack and fish cracker. However, since the variables were multifarious, it is not easy to decide 
which factors and what level of concentrations can be used in the fixed formulation. Therefore screening the important ingredients is urgently needed in such experiment.

Screening of ingredients, one at a time at arbitrary levels may take longer time as well as result in costly resources. Factorial designs provide solution to tackle the large number of sources category at a time. However, this method also requires a considerably large number of experiments (Davies, 1967). For example, in an experiment where 10 variables are needed to be evaluated, each of the variables would need a total of 1024 runs in the experiment. Because each run might be time-consuming and requires costly setting and resetting of machinery, it is often not feasible to conduct many different production runs for the experiment.

Plackett-Burman designs (Plackett \& Burman, 1946; Akhnazarova \& Kafarov, 1982) are providing particular help to address the problem. This method statistically can reduce the number of experiments tremendously thus saving time, glassware, chemicals and man- power (Srinivas et al., 1994; Carvalho et al., 1997). This means that the number of considered variables, are much less than the conventional method; for example, from 10 variables can be screened through 28 experiments only. This method does not determine the exact quantity, but it can provide some important information about each factor in relatively few experiments (Plackett \& Burman, 1946; DeMeo et al.,1985; Roseiro et al., 1992; Yu et al., 1997; Kalil et al., 2000; Long-Shan et al., 2003). It allows reliable short-listing of a few variables for further optimization.

Plackett-Burman design has been conducted to screen possible significant variables in many products (Srinivas et al., 1994; Guha et al., 2003; Bie et al., 2005; Chauhan et al., 2007; Modi \& Prakash, 2008). It is a useful tool for screening and searching the significant variable rapidly from a multivariable system. However, Plackett-Burman designs have not yet been applied to screen variables for basreng. Therefore, this study aimed to screen variables considered important in the production of basreng using Plackett Burman design. The experiments were run using two values, (high and low value) which described the range of variable values to produce the products.

\section{Material and Methods}

\subsection{Material}

Tapioca and potato flour were used in the experiment. The tapioca flour was produced by PT. Sungai Budi Lampung, while potato flour was collected from local market in bulky packaging. Catfish (Clarias sp.) were also used in the experiment, which were collected from local farmer in Parung, Bogor. The fish were killed, gutted, and washed before being used in the experiment. The fish were then deboned and minced using meat mincer fitted with $2.5 \mathrm{~mm}$ hole size, $70 \mathrm{~mm}$ diameter hole plate.

\subsection{Methods}

\subsubsection{Preparation of products}

Minced fish were mixed with salt for 5 min using Bibun Japan dough mixer then mixed with other ingredients for another $10 \mathrm{~min}$ until it became dough. The dough was rolled into $10 \mathrm{~cm}$ cylinder mold then steamed for $30 \mathrm{~min}$. The dough was then allowed to cool for $24 \mathrm{~h}$ at room temperature and then cut into 1 $\mathrm{mm}$ thin slice using manual cracker cutter. The slices were directly fried for $45 \mathrm{~min}$ and $60 \mathrm{~min}$ at temperature of $85^{\circ} \mathrm{C}$ and pressure of $70 \mathrm{cmHg}$ using vacuum frying machine. Basreng slices were allowed to cool then packed into plastic bag before being analyzed for its sensory and texture parameters.

\subsubsection{Design of experiment}

The amount of fish, tapioca flour, potato flour and frying time were selected as the possible variables which allegedly give significant influence on the final product (frying fish ball). These four variables tested are given in Table 1 along with their actual levels. Plackett-Burman design (Plackett \& Burman, 1946) was applied in the experiment, comprised four factors spanning over 12 runs with each factor fixed at two levels (low level and high level). The low level of fish was $200 \mathrm{~g}$ while the high level was $500 \mathrm{~g}$. Tapioca flour used in this experiment was weighed 600 and $200 \mathrm{~g}$ for high and low level, while for potato flour were 800 and $200 \mathrm{~g}$. Frying time was set into $45 \mathrm{~min}$ at 80 ${ }^{\circ} \mathrm{C}$ for low level and $60 \mathrm{~min}$ for high level. Other ingredients and process were set fixed since allegedly are not giving significant influence.

\subsubsection{Parameter analysis}

Basreng was analyzed for its hardness using texture analyzer (TA.XT2, Texture Technologies Corp., Scarsdale NY/Stable Micro System, Godalming, Surrey, England). This instrument also equipped with Texture Expert Software (v.120 Stable Micro System). 50-kg capacity texture analyzer was used, equipped with a $25-\mathrm{mm}$ aluminum probe to measure the texture profile of basreng. 
Table 1. Screening design for variables of sliced frying fish ball making

\begin{tabular}{ccccc}
\hline Formulation & Fish & $\begin{array}{c}\text { Tapioca } \\
\text { flour }\end{array}$ & $\begin{array}{c}\text { Potato } \\
\text { flour }\end{array}$ & $\begin{array}{c}\text { Frying } \\
\text { time }\end{array}$ \\
\hline 1 & 1 & -1 & 1 & -1 \\
2 & 1 & 1 & -1 & 1 \\
3 & -1 & 1 & 1 & -1 \\
4 & 1 & -1 & 1 & 1 \\
5 & 1 & 1 & -1 & 1 \\
6 & 1 & 1 & 1 & -1 \\
7 & -1 & 1 & 1 & 1 \\
8 & -1 & -1 & 1 & 1 \\
9 & -1 & -1 & -1 & 1 \\
10 & 1 & -1 & -1 & -1 \\
11 & -1 & 1 & -1 & -1 \\
12 & -1 & -1 & -1 & -1 \\
\hline
\end{tabular}

Note : -1 : Low value code; 1 : High value code.

\subsubsection{Sensory analysis}

\section{Hedonic test}

The basrengs were evaluated by hedonic test method using 1-7 scale score sheet following SNI 2346 (BSN, 2011). Low score means the product is less acceptable while high score means most acceptable. The attributes of appearance, color, odor, taste, texture, overall acceptance and those related to characteristics of variables were included in the score sheet. The samples were presented in random order and coded in five digits in small plates. The data for each attribute over the entire experimental basreng were subjected to regression analysis.

\section{Ranking test for the variables performance}

The variables were ranked for their effect on the individual attributes from best to worst (Mody \& Prakash, 2008). Best means that the products are having smallest possible negative effect on attribute while worst reflected much negative effect on the attribute. The direction of change (negative or positive) was with respect to what is expected from the final products. For example, for attribute of appearance, the higher scores were desirable so the ingredients with larger positive regression coefficients were much better and were ranked accordingly. These rankings were used to select the variables.

\section{Results and Discussion}

The mean scores of seven attributes of basreng are given in Table 2. Six attributes were analyzed through sensory panel test and one (hardness) attribute used textural device. It is apparent from Table
2 that the design formulations caused a large variation to the attributes scores. The mean score of appearance ranged from 2.58 to 5.33 ; color ranged from 2.58 to 5.58 ; odor ranged from 3.67 to 4.58 ; taste ranged from 3.67 to 5.33 ; texture ranged from 1.75 to 3.83 ; overall acceptance ranged from 2.09 to 4.45 and for hardness ranged from 3052.54 to $6754.96 \mathrm{~g}$. Table 2 also revealed that formula number one had the lowest average score for all of sensory attributes; while formula number five had the highest average score.

The changing of attributes values had a different expectation. Sensory attributes are expected to increase but the hardness is expected to decrease (Table 3). The increasing of sensory value was preferred by panelist which means better products. Thus, the observed variables should not appreciably give the effect of lowering the sensory attributes. In contrary, the observed variables were expected to decrease the hardness of the product. The result indicated that the hardness was not in accordance with the sensory values. The different method of analysis between sensory test and instrumental test seemed to be the cause of differences. The sensory test was involving panelists who were often associated with subjectivity. Therefore, training is important for panelists to analyze specific products to get an accurate data.

\subsection{Regression Analysis}

The results of coefficient regression of basreng can be seen in Table 4. The results showed that variables used in the experiment gave both positive and negative effects to the product. Positive effect means that the use of variable will increase the value of attribute, while negative effect means that the variable will decrease the value of attribute. The use of fish flesh in this 
Table 2. Mean score of fried basreng attribute

\begin{tabular}{cccccccc}
\hline & \multicolumn{7}{c}{ Attribute } \\
\cline { 2 - 8 } Formula & Appearance & Color & Odor & Taste & Texture & $\begin{array}{c}\text { Overall } \\
\text { acceptance }\end{array}$ & $\begin{array}{c}\text { Hardness } \\
\left(\mathbf{g} / \mathbf{c m}^{2} \mathbf{)}\right.\end{array}$ \\
\hline 1 & 2.58 & 2.58 & 3.67 & 3.67 & 1.75 & 2.09 & $5,245.27$ \\
2 & 5.42 & 5.58 & 4.08 & 4.08 & 2.25 & 3.18 & $6,754.96$ \\
3 & 5.17 & 5.17 & 4.33 & 5.00 & 3.75 & 4.00 & $5,318.09$ \\
4 & 4.50 & 4.00 & 4.42 & 4.83 & 3.33 & 3.36 & $5,949.61$ \\
5 & 5.33 & 5.25 & 4.17 & 5.33 & 3.83 & 4.45 & $5,215.41$ \\
6 & 5.17 & 5.17 & 4.50 & 4.92 & 3.25 & 3.82 & $6,310.76$ \\
7 & 4.97 & 4.97 & 4.33 & 4.83 & 2.83 & 3.36 & $6,330.78$ \\
8 & 4.83 & 4.83 & 4.17 & 4.25 & 2.42 & 3.09 & $6,442.74$ \\
9 & 4.92 & 5.17 & 4.58 & 4.92 & 2.83 & 4.09 & $3,906.19$ \\
10 & 3.25 & 3.33 & 4.17 & 4.42 & 2.25 & 3.00 & $3,051.54$ \\
11 & 5.33 & 5.50 & 4.50 & 4.50 & 2.42 & 3.73 & $3,103.68$ \\
12 & 3.25 & 3.58 & 3.92 & 3.92 & 2.25 & 3.00 & $3,957.53$ \\
\hline
\end{tabular}

Note: Higher value of sensory attributes means more acceptable, but in contrast, higher value of hardness means less acceptable.

Table 3. The expected attributes changes of basreng

\begin{tabular}{lcc}
\hline \multirow{2}{*}{ Attributes } & \multicolumn{2}{c}{ Changes } \\
\cline { 2 - 3 } & Increasing & Decreasing \\
\hline Appearance & Desirable & Undesirable \\
Color & Desirable & Undesirable \\
Odor & Desirable & Undesirable \\
Taste & Desirable & Undesirable \\
Texture & Desirable & Undesirable \\
Overall & Desirable & Undesirable \\
acceptance & & \\
Hardness & Undesirable & Desirable \\
\hline
\end{tabular}

experiment generally decreased the acceptance value of sensory attributes. The value of appearance, color, odor, taste, texture and overall acceptance decreased when the amount of fish flesh used increased. The amount of fish flesh used gave big negative effect to color, odor and appearance with coefficient value of $0.39,-0.39$ and -0.30 , respectively. These negative coefficient values were allegedly due to the dark color of the product resulted in this experiment as a result of Maillard reaction (Winarno, 1997), while most of the consumers prefer to a product with bright color. However, fish flesh gave less negative effect to the taste, texture and overall acceptance. They produced coefficient value close to zero which means that the variables only gave a slightly effects to product.

Furthermore, potato flour also decreased the acceptance value of odor and color. Other attributes such as appearance, taste, texture and overall acceptance increased when the amount of potato flour used also increased. The rest of variables, namely tapioca flour and frying time tended to have an opposite effect to fish flesh variable. Tapioca flour and frying time increased the acceptance value of panelists. Tapioca flour gave higher positive effect to 
Table 4. Regression coefficient for individual variables of each attribute of basreng

\begin{tabular}{|c|c|c|c|c|c|c|c|}
\hline \multirow[b]{2}{*}{ Variable } & \multicolumn{7}{|c|}{ Coefficient } \\
\hline & Appearance & Color & Odor & Taste & Texture & $\begin{array}{c}\text { Overall } \\
\text { acceptance }\end{array}$ & Hardness \\
\hline Fish & $-0.30^{*}$ & $-0.39^{*}$ & $-0.39^{*}$ & -0.08 & -0.03 & -0.05 & 243 \\
\hline Tapioca flour & $0.79^{*}$ & $0.79^{*}$ & $0.79^{*}$ & 0.10 & 0.24 & 0.36 & 419 \\
\hline Potato flour & 0.09 & -0.02 & -0.02 & 0.01 & 0.04 & 0.19 & $846^{*}$ \\
\hline Frying time & $0.55^{*}$ & $0.48^{\star}$ & $0.48^{*}$ & 0.07 & 0.17 & 0.22 & $680^{*}$ \\
\hline
\end{tabular}

Note:*Significantly different $(P<05)$.

the attribute of appearance, color and odor but lower positive effect to the attribute of taste, texture, overall acceptance and hardness.

In terms of hardness, almost all variables produced positive effect increasing the hardness of the product. The biggest effect was produced by variable of potato flour with coefficient value of 846 , followed by frying time, tapioca flour and fish with coefficient value of 680,419 and 243 , respectively. It was allegedly caused by the properties of variables where increasing the use of fish will increase the hardness due to their linear expansion. According to Kyaw et al. (2001), linear expansion would decrease as the amount of fish flesh increased. Yu (1993) also found that potato flour decreased linear expansion of fish crackers which meant increasing the hardness.

The decrease of acceptance value for attribute appearance, color and odor with addition of fish in this product could be due to the dark color as a result of Mailard reaction. Mailard reaction occurs between carbohydrate and primary amino acid compound producing dark brown products. King (2002) found that panelist preferred bright color product which was produced from less fish flesh. Heating treatment accelerated depolymeration of carbohydrate and protein which will be stimulating Mailard reaction (Winarno, 1997).

Other variables showed that the acceptance value of panelist increased in most attributes. Tapioca flour was considered to produce bright color so that the value of appearance, color and overall acceptance increased. Higher ratio of tapioca flour to the fish used would produce brighter products. In contrary, higher amount of fish flesh used will sharply increase the process of Mailard reactions, producing dark color (Susanto \& Saneto, 1994; Lavlinesia, 1995; King, 2002). It means that sufficient amount of fish should be applied to avoid the excessive Mailard reaction occurred.
In addition, the higher content of amylose and amylopectin in tapioca flour proposed the linear expansion producing a stretchable granule which made a brighter product (Yu, 1991; Huda et al., 2009). The linear expansion in fried cracker has been found to decrease as fish content increased (Yu et al., 1994; Paranginangin et al., 1997; Cheow et al., 1999; Huda et al., 2001; Kyaw et al., 2001).)

Meanwhile, potato flour gave less effect to most variables. It can be seen from coefficient value (close to 0 ) for appearance, color, odor, taste, texture and overall acceptance. This was allegedly caused by the color of potato flour itself. Noorakmar et al. (2012) found that the increase of potato flour decreased the whiteness of fried extruder fish crackers and lowering the acceptance rate of panelists. In opposite, frying time stimulated the Mailards reaction which was significantly affecting the appearance, odor and color. In this case, panelists were likely to prefer basreng with longer frying time.

\subsection{Variable Ranking}

The ranking of the variables for the seven attributes is given in Table 5. The higher rank stated in Table 5 indicates that the variable produced the most desirable properties while lower rank produced the less desirable properties. In summary, tapioca flour was the variable that produced the highest desirable properties followed by frying time, potato flour and fish. It was surprisingly that fish variable was only ranked at fourth which indicates that fish gave less effect to the final product. Therefore, it can be considered that for advanced stages, namely commercialization stage, less use of fish flesh is recommended because it will increase the company profit due to price margin reason.

The ranking of the ingredients and process for each attribute are based on the regression coefficient of 
Table 5. Variables ranking for different attributes of basreng

\begin{tabular}{lcccccccc}
\hline \multirow{2}{*}{ Variable } & \multicolumn{7}{c}{ Ranking* $^{*}$} \\
\cline { 2 - 9 } & Appearance & Color & Odor & Taste & Texture & $\begin{array}{c}\text { Overall } \\
\text { acceptance }\end{array}$ & Hardness Rank Sum \\
\hline Fish & 4 & 4 & 4 & 4 & 4 & 4 & 1 & 25 \\
Tapioca flour & 1 & 1 & 1 & 1 & 1 & 1 & 2 & 8 \\
Potato flour & 3 & 3 & 3 & 3 & 3 & 3 & 4 & 22 \\
Frying time & 2 & 2 & 2 & 2 & 2 & 2 & 3 & 15 \\
\hline
\end{tabular}

Note: *High rank means desirable; Low rank means undesirable.

the ingredient for the respective attributes. For further experiment, the lower rank variables (fish and potato flour), it will be put as its fixed value, however for the higher rank variables (tapioca flour and frying time), it will be selected for next factorial design experiment.

From this research, it was revealed that Plackett Burman method needs less experiment with only 14 runs compared to factorial or conventional method which need at least 48 runs with replications and will increase more for additional level of variables. This method had also successfully revealed the significance of variables in shorter time which means that it is requiring less cost and time.

\section{Conclusion}

From four variables (fish, tapioca flour, potato flour and frying time) considered in this experiment, two of them have been selected as significant variables (tapioca flour and frying time). Those two variables were proposed to be used for next factorial design experiment for further optimization study. Using the Plackett-Burman design, the four variables can be successfully screened in to few number of experiments which needs less cost and time.

\section{References}

Akhnazarova, S.,\& Kafarov, V. (1982). Experiment optimization in chemistry and chemical engineering. Moscow: Mir Publication.

Astawan, M.W. \& Astawan, M. (1989). Teknologi Pengolahan Pangan Hewani Tepat Guna, Edisi I. CV. Jakarta, Akademik Pressindo.

Bie, X., Lu, Z., Lu, F., \& Zeng, X. (2005). Screening the main factors affecting extraction of the antimicrobial substance from Bacillus sp. fmbJ using the PlackettBurman method. World Journal of Microbiology \& Biotechnology, 21(6), 925-928.

BSN 2346. (2011). A manual for sensory evaluation of fish product (in Indonesian). SNI. Jakarta.
Carvalho, C.M.L., Serralheiro, M.L.M., Cabral, J.M.S., \& Airebarros, M.R. (1997). Application of factorial design to the study of trans esterification reactions using cutinase in AOT-reversed micelles. Enzyme Microbial Technology, 27(2),117-123.

Chauhan, K., Trivedi, U., \& Patel, K.C. (2007). Statistical screening of medium components by PlackettBurman design for lactic acid production by Lactobacillus sp. KCP01 using date juice. Bioresource Technology, 98(1),98-103.

Cheow, C. S., Yu, Y.S., \& Howell, N.K. (1999). Effect of salt, sugar and monosodium glutamate on the viscoelastic properties of fish cracker ("Keropok”) gel. Journal of Food Processing and Preservation, 23(1), 21-37.

Davies, O. L. (1967). Design and analysis of industrial experiments. New York: Hafner Press.

DeMeo, M., Laget, M., Phan-Tan-Luu, R., Mathieu, D., \& Dumenil,G. (1985). Application of experimental designs for optimization of medium and culture conditions in fermentation. Bioscience, 4, 99-102.

Guha, M., Ali, S.Z., \& Bhattacharya, S. (2003). Screening of variables for extrusion of rice flour employing a Plackett-Burman design. Journal of Food Engineering, 57(2),135-144.

Huda, N., Aminah, A., \& Babji, A. S. (2001). Substitution of tapioca flour with surimi powder in traditional crackers (keropok palembang).16th Scientific Conference Nutrition Society of Malaysia, Kuala Lumpur. 24-25 March 2001.

Huda, N., Boni, I., \& Noryati, I. (2009). The effect of different ratios of Dory fish to tapioca flour on the linear expansion, oil absorption, colour and hardness of fish crackers. International Food Research Journal, 16, 159-165.

Iwe, O. M., Wolters, I., Gort, G., Stolp, W., \& Van Zuilichem, D. J. (1998). Behaviour of gelatinization and viscosity in soy-sweet potato mixtures by single screw extrusion: A response surface analysis. Journal of Food Engineering, 38(3), 369-379.

Kalil, S.J., Maugeri, F., \& Rodrigues, M.I. (2000). Response surface analysis and simulation as a tool for bioprocess design and optimization. Process Biochemistry, 35(6), 539-550. 
King, M. A. (2002). Development and sensory acceptability of crackers made from the big-eye fish (Branchy deuterusauritus). Food and Nutrition Bulletin, 23(2), 317-340.

Kyaw, Z.Y., Yu, S.Y., Cheow, C.S., Dzulkifly, M.H., \& Howell, N.K. (2001). Effect of fish to starch ratio on viscoelastic properties and microstructure of fish cracker (keropok) dough. International Journal of Food Science and Technology, 36(7), 741-747.

Lavlinesia. (1995). Study on variables affected the expansion and crispiness of fish crackers (in Indonesian).Thesis. Institut Pertanian Bogor. Bogor.

Long-Shan, T. L., Chieh-Chang, P., \& Bo-Kun, T. (2003). The influence of medium design on lovastatin production and pellet formation with a high-producing mutant of Aspergillusterreus in submerged cultures. Process Biochemistry, 38(9), 1317-1326.

Modi, V.K. \& Prakash, M. (2008). Quick and reliable screening of compatible ingredients for the formulation of extended meat cubes using PlackettBurman design. Swiss Society of Food Science and Technology, 41(5), 878-882.

Noorakmar, A. W., Cheow, C. S., Norizzah, A. R., Zahid, A., \& Ruzaina, I. (2012). Effect of orange sweet potato (Ipomoea batatas) flour on the physical properties of fried extruded fish crackers. International Food Research Journal, 19(2), 657-664.

Peranginangin, R., Fawzia, Y. N., Sugiyono, \& Mulyanah, I. (1997). Food additives and effect of thickeness on fish crackers quality. In Kuang H. K., Kim, L. L. \& Yong, L. P. (Eds). Proceeding of the seminar on the advances in fish processing technology in Southeast Asia in relation to quality management. Singapore. MFRDSEAFDEC, p. 106-114.

Plackett, R. L., \& Burman, J. P. (1946). The design of optimum multifactorial experiments. Biometrika, 33(4), 305-325.

Purnomo. (1997). Animal processing technology related to food safety in 21 st century. Inauguration Professor Speech. Universitas Brawijaya. Malang.
Roseiro, J. C., Esgalhado, M. E., \& Amaral Collaco, M. T. (1992). Medium development for xanthan production. Process Biochemistry, 27(3), 167-175.

Sunarlim, R. (1994). The effect of $\mathrm{NaCl}$ on fish ball (in Indonesian). Delivering at national seminar on livestock to support disadvantage rural area. Semarang.

Susanto, T. \& Saneto, B. (1994). Technology of agricultural processing (in Indonesian). Bina IImu, Surabaya.

Srinivas, M.R.S., Naginchand, \& Lonsane, B.K. (1994). Use of Plackett-Burman design for rapid screening of several nitrogen sources, growth/ product promoters, minerals and enzyme inducers for the production of alpha-galactosidase by Aspergillusniger MRSS 234 in solid state fermentation. Bioprocess Engineering, 10(3),139144.

Usmiati, S. (2009). Healthy meatball (in Indonesian). Agricultural Research and Development News, 31, 13-14.

Winarno, F.G. (1997). Food chemistry and nutrition (in Indonesian). Jakarta: Gramedia Pustaka Utama.

Yu, S. Y., Chai, Y. K. \& Motohiro, T. (1994). Utilization of protein from fish ball processing wash water in fish crackers (keropok). Journal Food Processing and Preservation, 18(6), 453-459.

Yu, S. Y. (1991). Acceptability of fish crackers (keropok) made from different type of flour. Asean Food Journal, 6(3), 114-116.

Yu, S. Y. (1993). Effect of rice starch on linear expansion of fish crackers (keropok). Tropical Science, 33(3), 319-21.

Yu, X., Hallett, S. G., \& Sheppard, J. (1997). Application of the Plackett-Burman experimental design to evaluate nutritional requirements for the production of Colletotrichum coccodes spores. Applied Microbiology and Biotechnology, 47(3), 301-305. 